\title{
Preliminary study on Contrast Flow Analysis of thoracic transforaminal epidural block
}

\author{
Ki Beom Park \\ Anesthesiology and Pain medicine, Keimyung University Dongsan Hospital, Korea
}

\section{Back ground}

Thoracic transforaminal epidural block (TTFEB) usually performed to treat herpes zoster or postherpetic neuralgia (PHN). This study investigated the contrast dye spread patterns of $1-\mathrm{ml}$ to $3-\mathrm{ml}$ TTFEB

\section{Methods}

A total of 26 patients with herpes zoster or PHN were enrolled in this study. All participants received $1 \mathrm{ml}, 2 \mathrm{ml}$, or $3 \mathrm{ml}$ of contrast medium. Results were divided into Groups A, B and C based on the volume $(1,2$, or $3 \mathrm{ml})$, with $n=26$ for each group. To analyze spread according to the contrast volume, $1 \mathrm{ml}$ of contrast medium was injected at $5 \mathrm{~s}$ intervals (once for $1 \mathrm{ml}$ in Group A, twice for $2 \mathrm{ml}$ in Group B, and three times for $3 \mathrm{ml}$ in Group C). After the injection of contrast medium, the spread levels were estimated in both the lateral and anteroposterior (AP) images using fluoroscopy.
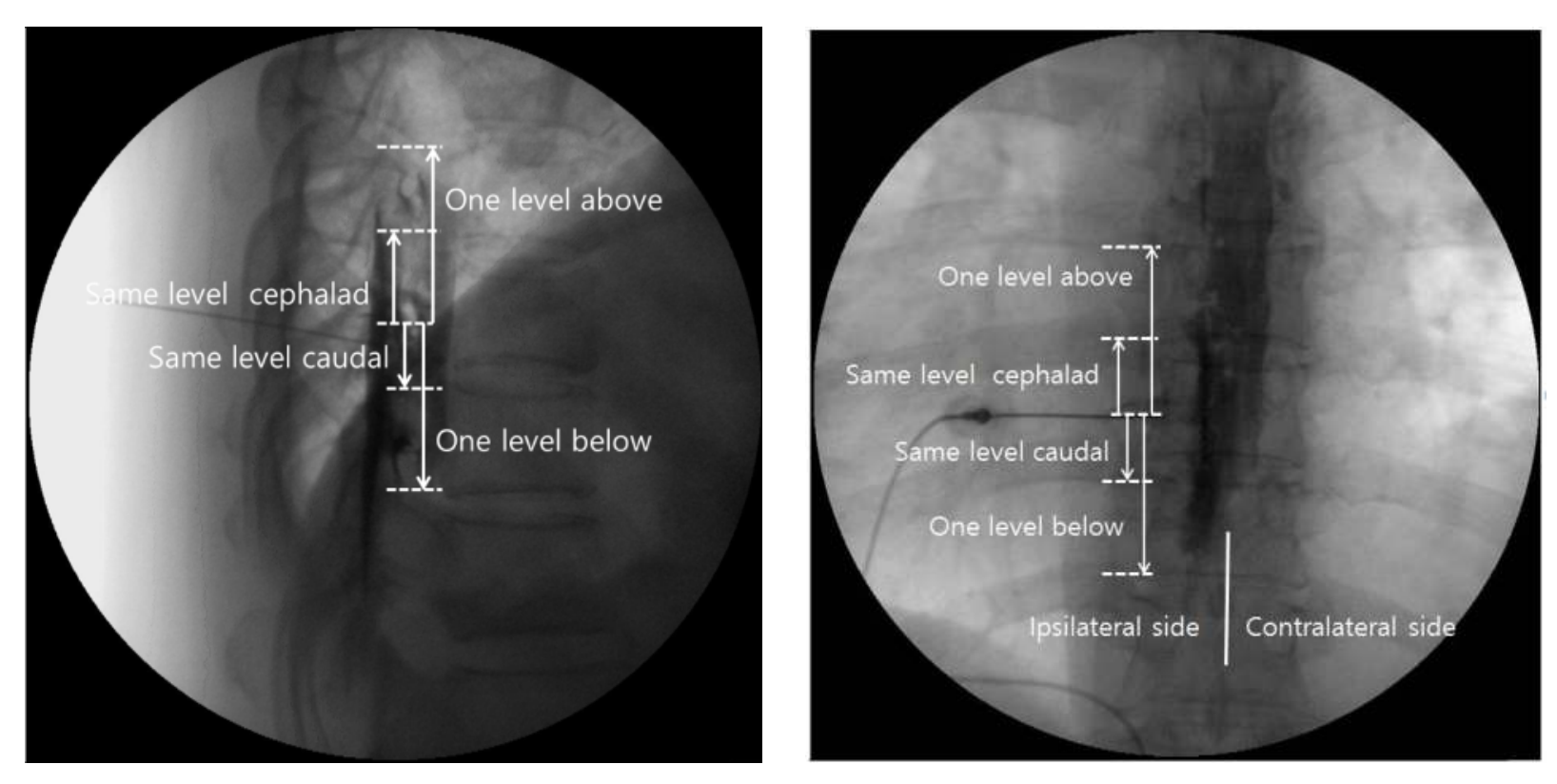

Fig. 1. (a) Lateral radiograph shows 2-level cephalad and 2-level caudal spread. (b) AP radiograph defined ipsilateral and contralaeral side.

\section{Results}

A total of 26 patients with herpes zoster or PHN were enrolled in this study; 11 patients were male, and 15 patients were female. The average age was $64.8 \pm 12.2$ years. Average duration of symptoms before admission was $10.3 \pm 13.6$ weeks. the nine patients included in the upper thoracic group, eight were in the middle and nine were in the lower thoracic groups. The total spread level of $3 \mathrm{ml}$ of contrast medium, were 6.00 [4.50-7.50] in the upper thoracic group, 5.50 [4.25-7.75] in the middle thoracic group, and 6.00 [4.00-6.00] in the lower thoracic group. Bilateral (ipsilateral and contralateral) epidural spread of contrast medium on the AP image was exhibited in $85 \%(22 / 26)$ of cases after the $3 \mathrm{ml}$ contrast medium injection. Both ventral and dorsal spread of the $3 \mathrm{ml}$ contrast medium injection was revealed in $88 \%(23 / 26)$ of cases
Table 1. Contrast medium spread in cephalad and caudal directions, by group: lateral image (presented as median [interquartile range] )

\begin{tabular}{|c|c|c|c|}
\hline & $\begin{array}{c}\text { Group A } \\
(\mathrm{n}=26)\end{array}$ & $\begin{array}{c}\text { Group B } \\
(\mathrm{n}=26)\end{array}$ & $\begin{array}{l}\text { Group C } \\
(\mathrm{n}=26)\end{array}$ \\
\hline Cephalad spread & $2[1-2]^{*}$ & $2.5[2-3]^{{ }^{*}}$ & $3[2-4]^{\dagger^{*}}$ \\
\hline Caudal spread & $1[1-2]$ & $2[2-3]^{\ddagger}$ & $2[2-3]^{\ddagger}$ \\
\hline Total spread & $3[2-4]$ & $4[4-5]$ & $6[4-6.75]$ \\
\hline
\end{tabular}

$\dagger$ : In cephalad spread, the difference among groups are significant $(P$ value $<0.001$ ) and the direction is Group A < Group B < Group C.

$\ddagger$ : In caudal spread, the difference among groups are significant $(P$-value $<0.001$ ) and the direction is Group A < Group B < Group C.

*: In bidirectional spread, the difference within group (cephalad vs caudal) are significant $(P$-value $<0.05)$ and direction is caudal $<$ cephalad

Table 2. Comparison of contrast medium spread between ipsilateral and contralateral sides following 3-ml contrast medium injection: anteroposterior image (presented as median [interquartile range])

\begin{tabular}{|c|c|c|}
\hline \multirow{2}{*}{} & \multicolumn{2}{|c|}{ Group C (n=26) } \\
\hline Ipsilateral spread & Cephalad† & $3[2-4]$ \\
\hline & Caudal $\neq$ & $2[2-3]$ \\
\hline & Total $^{*}$ & $5[3.75-6]$ \\
\hline Contralateral spread & Cephalad & $2[2-4]$ \\
\hline & Caudal & $2[1-2.5]$ \\
\hline & Total & $4[3-5.25]$ \\
\hline
\end{tabular}

$\dagger$ : In cephalad spread, the difference between ipsilateral and contralateral side is significant $(P<0.05)$ and the direction is contralateral < ipsilateral.

$\ddagger$ : In caudal direction, the difference between ipsilateral and contralateral side is significant $(P<0.01)$ and the direction is contralateral $<$ ipsilateral.

*: In total spread, the difference between ipsilateral and contralateral is significant $(P<0.001)$ and the direction is contralateral $<$ ipsilateral.

\section{Discussion}

In this study, contrast medium spread in the cephalad direction was wider than in the caudal direction on the lateral view in all three groups This contrast medium spread pattern is similar in the thoracic interlaminar epidural block (TIEB).

\section{Reference}

Yokoyama M, Hanazaki M, Fujii H, Mizobuchi S, Nakatsuka H, Takahashi T, et al. Correlation between the distribution of contrast medium and the extent of blockade during epidural anesthesia. Anesthesiology 2004; 100: 1504-10 